\title{
Redefiniciones de la modernidad ${ }^{1}$
}

Peter Wagner*

\section{Resumen}

El concepto de modernidad necesita ser redefinido si quiere seguir siendo fructífero en la investigación sociológica y en el diagnóstico de nuestro tiempo. Este artículo sugiere que tal definición debe implicar una ampliación del horizonte temporal y una extensión del alcance espacial de lo que se entiende por modernidad. Esta demanda está hecha a través de un movimiento en aparentemente otra dirección: reconociendo que el concepto actual prevaleciente de modernidad tiene su raíz en la historia europea de los siglos XIX y XX, la tradición sociológica de definir la modernidad es releída en este contexto espacio-temporal particular. Tal análisis ayuda a identificar los actuales límites del concepto así como los pasos necesarios para superarlos.

Palabras clave: Europa - modernidad - historia mundial.

\begin{abstract}
This concept of modernity needs to be redefined if it is to remain fruitful in sociological research and for a diagnosis of our time. This article suggests that such redefinition must entail a broadening of the temporal horizon and a widening of the spatial scope of what is referred to as modernity. The claim is made through a move in apparently the opposite direction: recognizing that the currently prevailing concept of modernity is rooted in the European history of the nineteenth and twentieth centuries, the sociological tradition of defining modernity is re-read in this particular spatio-temporal context. Such an analysis helps identifying the current limits of the concept as well as the steps necessary for overcoming them.
\end{abstract}

Keywords: Europe - modernity - world-history.

1 Presentación realizada en el Seminario Internacional del Doctorado en Ciencias Sociales de la Universidad de Chile. Traducción de Ernesto Rubio.

* ICREA y Universidad de Barcelona 


\section{INTRODUCCIÓN}

A lo largo de las tres últimas décadas, el mundo intelectual ha gastado no pocas energías en proponer, criticar y volver a proponer un concepto de modernidad. No quiero detenerme en los detalles de este debate ahora mismo. En lugar de eso, empezaré haciendo una síntesis del mismo planteando dos cuestiones claves que han sido -y siguen siendo- sus temas fundamentales. Las dos surgieron como crítica al estado del debate en la sociología alrededor del año 1970: la primera consiste en que la sociología anterior había sugerido que, una vez alcanzada, la modernidad permanecería inalterable y no sufriría más cambios. Esta suposición fue cuestionada de manera radical por el debate alrededor del comienzo de la posmodernidad, y después volvió a tratarse, desde otra perspectiva, tras ser sugerida la idea de que la modernidad estaba sufriendo, de hecho, una incuestionable y pronunciada transformación social. Esta primera cuestión apunta que la modernidad necesitaba ser redefinida a partir de su temporalidad e historicidad, es decir, de su capacidad para sufrir transformaciones. La segunda cuestión parte del hecho de que la sociología anterior había asumido que la modernidad se originó en Europa, se desarrolló en el Viejo Continente y en Norteamérica, y que solo después se propagó al resto del mundo. Esta suposición ha sido criticada tanto por los estudiosos de fuera de Europa bajo distintos epígrafes -postcolonial, decolonial, dependencia-, como por los recientes investigadores de la historia mundial que tratan de escribir una versión menos asimétrica de una historia siempre entrelazada. Mientras que el primero de los dos temas tiene que ver con la temporalidad de la modernidad, el segundo versa acerca de su posición espacial, de su espacialidad.

Tanto una crítica como la otra están de sobra justificadas y eran totalmente necesarias. Las dos logran señalar con éxito los defectos y las debilidades del pensamiento predominante acerca de la modernidad. Sin embargo, las alternativas que proponen, o algunos de los elementos que las componen, son mucho menos convincentes. Los orígenes de este desequilibrio se encuentran, en mi opinión, en el hecho de que el concepto europeo -o el occidental, o el del Norte- de la modernidad es percibido como un concepto hegemónico; y lo que se debería hacer con la hegemonía es criticarla más que entenderla. En lo que queda de presentación trataré de hacer justamente lo contrario: intentaré entender en qué sentido las concepciones sociológicas de la modernidad están enraizadas en el espacio y el tiempo de la historia europea, tomando esta como parte de la historia mundial. Siguiendo el título de esta serie de seminarios, exploraré cómo las tendencias del pensamiento social necesitan ser entendidas dentro del contexto de las transformaciones de la sociedad. Y a partir de ese ejercicio, me haré la pregunta de en qué sentido necesita la modernidad ser redefinida para poder verdaderamente tratar las situaciones sociales a lo largo de espacios y tiempos más prolongados.

Los estudiosos a los que ahora nos referimos como sociólogos de la modernidad trataron de comprender el siglo XIX europeo. Pero no eran del todo conscientes de que fuese eso lo que estaban haciendo, o, mejor dicho, de que lo que hacían no era posiblemente lo mismo que "teorizar la modernidad". La canonización de la sociología ha olvidado que los estudiosos eran personas, que tenían unas intenciones y escribían en un determinado contexto. Como consecuencia de esto, la tendencia ha sido confundir la "modernidad" 
con el siglo XIX europeo. El problema sigue vigente actualmente, y las observaciones siguientes pretenden plantear algunas cuestiones que surgen de esa confusión.

El razonamiento recorrerá seis etapas. La primera: es preciso captar las características históricas claves de la sociología europea en el sentido que le otorgaremos aquí al término. En esta presentación, el surgimiento de la sociología europea se asociará al "largo siglo XIX" (Eric Hobsbawm), que va desde la Revolución Francesa hasta la Primera Guerra Mundial, en vez de adoptar la concepción más habitual y estrecha de la "sociología clásica", que acota el período entre 1890 y 1920. En una segunda etapa, las características claves de las sociedades europeas durante ese mismo período serán brevemente discutidas a la luz del estado actual del conocimiento, siguiendo de cerca los recientes trabajos acerca de la "historia mundial" que sitúan a Europa en un contexto global, y lo hacen de forma mucho más explícita de lo que lo había hecho la historiografía anterior. De esta confrontación entre la historia intelectual de la sociología y la historiografía de la región, sobre la que se supone trataba esa sociología, surgen tres preguntas que serán formuladas en las tres secciones siguientes. La tercera etapa explorará así la cuestión de hasta qué punto el diagnóstico sociológico de las sociedades europeas y las transformaciones que estas han sufrido durante el siglo XIX ha supuesto la confección de una teoría sociológica de la modernidad. Sea este el caso o no, en la cuarta etapa se planteará la cuestión de si las experiencias europeas del siglo XX modificaron en algo el análisis de la modernidad que había sido elaborado a partir de las experiencias del XIX. Además de esto, y en quinto lugar, será preciso hacerse la pregunta de cómo han relacionado los sociólogos de la modernidad la experiencia europea con la de otras partes del mundo. Tras intentar contestar brevemente a estas tres cuestiones, las conclusiones tendrán como objetivo explorar qué características puede tener hoy en día una sociología mundial de la modernidad que con toda probabilidad se verá obligada a recurrir y también a superar a la sociología europea de la modernidad².

\section{LA IDENTIFICACIÓN DE LA SOCIOLOGÍA EUROPEA DE LA MODERNIDAD}

Entender la sociología de la modernidad como la reflexión acerca de las relaciones sociales durante el largo siglo XIX europeo -que va desde 1789 hasta 1914- significa hacer mención a una gran cantidad de estudiosos: desde Henri de Saint-Simon y G.W.F. Hegel hasta Alexis de Tocqueville, y desde Karl Marx hasta Emile Durkheim, Max Weber y Georg Simmel. Dejando a un lado todas las diferencias existentes, todos estos autores tienen en común que identificaron una ruptura profunda en la vida social, una ruptura que había provocado, o que provocaría, una forma radicalmente nueva de relaciones y de estructura social. Pese a que eligieron diferentes términos para caracterizar la ruptura y las transformaciones sociales correspondientes, y que difirieron a la hora de identificar los acontecimientos más significativos para la transformación (estas cuestiones las retomaremos más adelante), el tema fundamental para todos fue el análisis de la formación social emergente, tanto por la cuestión de su novedad como por el hecho de que esta marcaría el presente y el futuro.

2 Este trabajo es parte del proyecto "Trajectories of modernity: comparing non-European and European varieties" (TRAMOD; Advanced Grant N 249438) financiado por el European Research Council. 
Por todas esas razones, podemos considerar que las obras de estos autores constituyeron la sociología europea de la modernidad. Más que desarrollar un análisis institucional de la modernidad, tomando esta como una nueva configuración social establecida, estos estudiosos, preocupados por el peso de la historia, trataron de captar el significado y las consecuencias de la "gran transformación" de la que habían sido testigos y para la que necesitaban nuevos conceptos.

La modernidad, resumiendo las perspectivas de esos autores, estaba caracterizada por una serie de rasgos que habían estado ausentes del mundo social antes de la ruptura, o habían tenido tan solo una importancia tangencial. La modernidad trajo consigo una nueva forma de estar-en-el-mundo y unas actitudes novedosas tanto respecto del mundo como en relación con los demás seres humanos, que fueron reflejadas por conceptos tales como la libertad abstracta, la racionalidad instrumental individual (el "cálculo egoísta" del que hablaban Marx y Engels), el individualismo y el racionalismo occidental. La nueva constelación social en la que los seres humanos se encuentran y en la que esas actitudes se desarrollan, es definida, por su parte, por términos como industria, división del trabajo, democracia, sociedad burguesa, clase trabajadora y capitalismo. Pese a que se haga mención de algunos desarrollos anteriores, todos estos autores afirman que esas actitudes y constelaciones aparecieron -o alcanzaron una posición dominante- en Europa a partir de finales del siglo XVIII y principios del XIX. Antes de entrar a analizar en profundidad los programas teóricos, deberemos explorar brevemente el contexto histórico con el que se enfrentaban estos autores.

\section{EL SIGLO XIX EUROPEO}

¿Qué era Europa en el siglo XIX? Para contestar con la debida brevedad a esta pregunta no investigaremos directamente lo que estos autores conocían acerca del mundo que les era contemporáneo, sino que usaremos la información que tenemos hoy a nuestra disposición, y en particular las importantes contribuciones del recientemente desarrollado campo de la "historia mundial" (Pomeranz, 2000; Baily, 2004; Osterhammel, 2008).

Según la perspectiva actual, a finales del siglo XVIII, la vida económica y social no era muy distinta en Europa y en otras partes del mundo, en particular, en Asia. A finales del XIX, sin embargo, el mundo estaba dominado por las potencias europeas: este hecho fue el resultado de una combinación de superioridad militar, ocupación colonial y asentamientos en territorios no europeos. Por consecuencia, nació un intercambio económico cuyas condiciones eran siempre dictadas desde Europa. Además de esto, y debido en parte a esta dominación, las élites de las sociedades no europeas se veían a sí mismas como rezagadas, y a menudo consideraban que esta debilidad y lentitud en los cambios estaba causada por la falta de ideas y de conceptos europeos. Para poner remedio a esta situación, trataron de importar y adoptar los conceptos procedentes de Europa que les permitieran reordenar la vida social, incluyendo aquí conceptos propios de la sociología europea.

En nuestro días, contamos con buenas razones para suponer que "la gran divergencia" (Pomeranz) entre Europa y otras regiones del mundo que surgió a lo largo del siglo XIX se trataba de un suceso contingente. Lo que lo condicionó fueron las relaciones comerciales 
que, de forma triangular, se habían ido desarrollando lentamente en el Atlántico en los tres siglos precedentes por medio del uso de la mano de obra africana, el suelo americano -que estaba bajo superioridad militar europea-, y del hecho de que, a finales del siglo XVIII, Europa Occidental se había liberado de una serie de limitaciones al crecimiento económico; limitaciones que había compartido hasta entonces con otras regiones asiáticas. Los estudios actuales sugieren, por su parte, que en la historia intraeuropea anterior a ese momento no existen demasiados antecedentes que preparasen el terreno para el "despegue" europeo (Walt Rostow). Ni los regímenes legales, en particular los referentes a los derechos de propiedad, ni los avances tecnológicos que aparecieron tras la que sería conocida después como Revolución Científica, ni la aparición de las universidades a principios del segundo milenio de la era cristiana como espacios autónomos para el debate y la investigación, o de las ciudades como espacios para la organización político-económica, ni la división del poder entre el Papa y el Emperador, marcaron una diferencia sustancial entre Europa y otras regiones del mundo que pueda ser capaz de explicar los desarrollos del siglo XIX. Sea cual sea el impacto que algunos de estos factores pudiesen llegar a tener, su influencia es minúscula si se la compara con los efectos del nuevo régimen de comercio atlántico.

Es más, parece perder fuerza la idea de que la "causa" de la ruptura histórica está en la combinación de un acontecimiento socioeconómico y uno intelectual; concretamente, el ascenso de la burguesía, y la aparición de la economía política y la idea asociada de libertad de mercado. Independientemente de si concebimos el primero de estos hechos como causante del segundo, o el segundo como un factor que allanó el camino del primero, se ha exagerado la capacidad transformadora tanto de uno como del otro. A principios del siglo XIX, las nuevas posibilidades económicas creadas por las conexiones atlánticas empezaron a ser percibidas. Pero de todo esto no surgió ningún nuevo mundo dominado por actores nuevos. En lugar de eso, y como respuesta a las nuevas posibilidades, las viejas élites aristocráticas fueron cambiando gradualmente su perspectiva y comenzaron a forjar nuevas alianzas, sin incorporar ninguna de las nuevas visiones radicales procedentes de la Revolución Francesa y de la economía política, e imponiendo su fuerza en la nueva constelación a través de una violencia ejercida tanto en sus países de origen como en el extranjero. En Europa, el período transcurrido entre el Congreso de Viena de 1815 y el Tratado de Versalles de 1919 no fue ni tan pacífico ni tan revolucionario como se ha afirmado en distintas ocasiones. Es cierto que fue entonces cuando se produjo el ascenso de la industria y, con ella, de la riqueza y del poder: categorías, ambas, distribuidas de manera enormemente asimétrica. Pero la transformación sociopolítica, que en muchas ocasiones se ha querido ver como acompañante de la transformación técnico-económica, tuvo un carácter muy limitado (Mayer, 1981; Halperin, 2004; Stråth, de próxima aparición).

Así, el cambio fundamental entre 1800 y 1900 fue el ascenso de Europa a la dominación del mundo, un ascenso basado en la explotación de las nuevas posibilidades técnico-económicas que surgían gracias a la aparición de la división atlántica del trabajo. En un primer momento este hecho fue percibido por Marx y Engels, quienes, en la breve y contundente explicación de las recientes transformaciones sociales que aparece en el Manifiesto Comunista, afirman que el "descubrimiento de América [y] doblar el cabo de Buena Esperanza" dio un "impulso 
nunca conocido anteriormente" a la burguesía revolucionaria. Pero incluso en su texto, esta afirmación no es más que un comentario con el que da inicio una de sus reflexiones y no tiene consecuencias en el análisis posterior. Por lo demás, los estudiosos tendían a ver los cambios en Europa como una historia "endógena" y autopropulsada, determinada ya sea por una lógica de la historia -que se extiende desde los logros funcionales y la selección de las soluciones superiores hasta las dinámicas determinadas de la lucha de clases-, o bien, al menos, como productora de unos resultados inexorables una vez se ha tomado un determinado camino. En otras palabras, ahora podemos afirmar que los sociólogos del siglo XIX se equivocaron al definir las causas de las transformaciones sociales que se produjeron en Europa en ese mismo período. ¿Qué implicaciones tiene esto en su percepción de una modernidad que, según su punto de vista, se había producido a partir de esas supuestas causas?

\section{III. ¿HAY -HA HABIDO- UNA TEORÍA SOCIOLÓGICA EUROPEA DE LA MODERNIDAD?}

Para la sociología europea de la modernidad hubo dos observaciones que fueron cruciales. La primera consistió en la percepción de una ruptura considerablemente radical en la historia, ejemplificada por la Revolución Industrial y la Revolución Francesa, si bien las relaciones entre estos dos sucesos no fueron convenientemente estudiadas y el segundo fue infrateorizado, con algunas pocas excepciones, como Tocqueville, y también, en cierta medida, Lorenz von Stein. La segunda, como ya se ha mencionado anteriormente, consistió en percibir una dinámica de la historia, que quizá no estaba sociológicamente explícita en Hegel, pero que se volvió evidente a partir de mediados del siglo XIX, con el Manifiesto Comunista de 1848 como claro ejemplo. En relación con estas dos percepciones, la sociología europea de la modernidad diagnosticó una destrucción radical de la fábrica existente de relaciones sociales, hecho que desataría a su vez unas dinámicas sin precedentes.

Como consecuencia de esto, la sociología europea de la modernidad llevó a cabo predominantemente un análisis de movimiento; ofreció unos pocos "retratos" de la modernidad. Emile Durkheim es la principal excepción europea a lo que Parsons y la sociología de la "sociedad moderna", con base en Estados Unidos, construirían posteriormente. Tal afirmación podrá parecer infundada a primera vista ahora que hemos acabado pensando la "modernidad" con la imagen parsoniana siempre presente de la "sociedad moderna". Pero podemos cuestionar su validez con una breve mirada retrospectiva al punto de vista desarrollado por Parsons. Este ofreció una imagen institucional de la sociedad, diferenciada en subsistemas con su propia lógica, incluyendo un sistema económico basado en el mercado de intercambio regulado por el dinero y un sistema político respaldado por las reglas formales e impersonales de una administración racional. Esta imagen utilizaba elementos de la sociología europea de la modernidad, pero los reunía con la intención de que guardaran una coherencia y una estabilidad que no es posible encontrar en su versión original; de nuevo con la excepción de Durkheim. Siguiendo a los economistas políticos, Marx analizó el mercado de intercambio regulado por el dinero, pero insistió en el antagonismo existente en las relaciones sociales subyacentes que impedirían que cualquier mercado se estabilizara en un sistema económico. La "morada hecha de acero" (mal traducida como "jaula de 
hierro") de Weber, es también un "retrato" que sin duda trabaja una metáfora visual para ilustrar el resultado de la racionalización, pero Weber se mostraba escéptico acerca de la estabilidad de esa construcción, y esperaba más bien que fuese puesta en tela de juicio y posiblemente desmantelada por su falta de conveniencia.

La razón de que la sociología europea de la modernidad hiciera hincapié en ciertas tendencias en vez de proporcionar un modelo institucional de sociedad es algo que se puede entender fácilmente si se piensa en el contexto de la época. En los primeros años del siglo XX, las sociedades no se ajustaban a ningún modelo de coherencia: muchas de ellas no eran Estados-naciones, sino imperios coloniales; no eran democracias inclusivas, sino oligarquías que operaban por sufragio censitario; existía el capitalismo, pero la autorregulación del mercado había resultado deficiente y el intercambio económico estaba altamente regulado; las iglesias cristianas operaban en su mayoría en íntima alianza institucional con el Estado; la idea del individuo autónomo se limitaba en gran parte a los burgueses y "bohemios", modelos emprendedores y artísticos de autorrealización; es decir, grupos muy reducidos dentro de la sociedad.

Al recurrir a las tendencias, se posibilitó que los problemas empíricos resultasen aceptables, al proyectar la completa realización de la modernidad en un futuro indefinido. Podemos decir que la sociología europea de la modernidad se implicó con la apertura del horizonte-temporal llevada a cabo por el pensamiento sociopolítico desde finales del siglo XVIII en adelante (Koselleck, 1979), oscilando entre las proyecciones más deterministas y teleológicas de una modernidad futura, por un lado, y la indecisión y el escepticismo, por el otro. Los sociólogos participaron sin duda de un modo de pensar que era en líneas generales evolucionista, y que se vio generado por el en apariencia imparable ascenso de Europa durante el siglo XIX. Muy pocos, sin embargo, adoptaron una visión rotunda y lineal del progreso a lo largo de la historia, y de Europa como el territorio donde habría de tener lugar ese progreso. Recordemos la tensión en la obra de Marx entre la identificación de las leyes de la lucha de clases y de la competencia capitalista, por un lado, y la preocupación acerca de la posible "ruina común de las clases en pugna", por el otro; y de forma similar, el análisis de Weber de los procesos racionalizadores en curso, por un lado, en oposición a su conjetura acerca del regreso de los viejos valores y el ascenso de los nuevos profetas, por el otro. La observación de las novedosas formas sociales (estructuras) y de los nuevos seres humanos (individuos racionales) constituyó un programa para el pensamiento y para la acción; no condujo directamente a una teoría de la modernidad porque la "modernidad" observada era demasiado inestable y estaba sometida a demasiadas tensiones. Con la única posible excepción de Durkheim, ninguna de las figuras más importante de la sociología europea del siglo XIX y principios del XX compuso una teoría plenamente desarrollada acerca de la "sociedad moderna".

La breve reconstrucción trazada hasta ahora puede haber dejado una cuestión abierta: a diferencia de las versiones habituales de la historia de la sociología como disciplina, no hemos reservado ningún espacio particular a lo que solemos llamar la "sociología clásica". Y desde luego, mantenemos que es el trabajo de Parsons y de sus lectores europeos tras la Segunda Guerra Mundial el que, a partir de las obras de los "sociólogos 
clásicos", destiló una sociología de la modernidad, que se ha perpetuado en los libros de texto actuales, y que no existía bajo ningún nombre o sustancia alrededor de 1900, o incluso de 1920. La "sociología clásica", sin embargo, es un fenómeno identificable, cuya aparición puede ser entendida a través de la confluencia de dos situaciones. Por un lado, Durkheim, Weber, Pareto y Simmel trabajaron durante un período de transformación de las instituciones académicas. Tras el paulatino "ascenso de la universidad orientada hacia la investigación" (Wittrock, 1985) que tuvo lugar en el siglo XIX, el período en torno al 1900 fue un momento de constitución disciplinaria en lo que serían las ciencias sociales, en el que se emularían los cambios que habían tenido lugar con anterioridad en las ciencias naturales. Durkheim era bien consciente de esta situación y dedicó buena parte de su energía intelectual a la creación sociológica como disciplina diferenciada. Pero muchos de sus contemporáneos escribieron tratados que definían el campo de la sociología e intentaban acotar el espacio intelectual-institucional de investigación y reflexión (Wagner, 1991; véase ahora Borch, 2012). En lo esencial, por otro lado, estos autores se enfrentaban a una transformación social que podemos ahora reconocer como una primera crisis del tipo de modernidad que era consecuencia de los sucesos del siglo XIX, y también del desarrollo de las capacidades para la acción colectiva -a través de los Estados, las naciones, las clases- para contrarrestar las problemáticas consecuencias de las tendencias que se habían puesto en funcionamiento (Wagner, 1994; Polanyi, 1944, debe servir como retrato de esto, como veremos a continuación). Durkheim, Weber, Pareto y Simmel ya no tenían la perspectiva de estar escribiendo en los albores de una nueva era, tal y como Saint-Simon, Hegel, Tocqueville e incluso Marx pudieron Ilegar a pensar. Lo que hacían ahora era echar la vista atrás, examinar una transformación de gran magnitud y tratar de evaluar los resultados de la misma. De forma significativa, no tenían ninguna certeza acerca de cómo debían llevar a cabo esa evaluación, ni de cuáles podrían ser los resultados. La incertidumbre primera propició textos acerca de la filosofía y metodología de las ciencias sociales de una sofisticación a menudo muy elevada; la segunda, diagnósticos dominados por la ambivalencia a los que hemos hecho referencia antes. La "modernidad" que experimentaban los "sociólogos clásicos" era todo excepto estable; y ellos eran conscientes de esto. Si se estabilizaría o no, dependía en gran medida de cómo se presentase el futuro, un tiempo en el que estos supuestos fundadores de la sociología europea de la modernidad ya habrían dejado de existir.

\section{IV. ¿CÓMO AFRONTÓ LA SOCIOLOGÍA EUROPEA DE LAMODERNIDAD LAS EXPERIENCIAS DEL SIGLO XX?}

Para no extendernos demasiado, diremos que dicho futuro se tornó sombrío. La experiencia de la Primera Guerra Mundial hizo tambalear las perspectivas más optimistas. Como consecuencia de esto, la propia sociología sufrió una crisis intelectual y se transformó básicamente en una filosofía social neoidealista, escindida de la investigación social empírica que iba creciendo lentamente (Heilbron, 1985, en Francia; Wagner, 1990, desde una perspectiva comparativa). Lo que se conocería como sociología clásica desapareció con la muerte de sus fundadores: Durkheim murió en 1917; Simmel en 1918; Weber en 1920; Vilfredo Pareto en 1923. Su problemática la continuaría un reducido grupo de autores, 
eminentes teóricos de la modernidad, cuyos trabajos, sin embargo, no se integraron en el canon de la sociología. Haremos mención tan solo a tres de esos estudiosos.

En 1937, Karl Manheim publicó su libro El hombre y la sociedad en la época de crisis, en el que proponía considerar la "democratización fundamental" como fuerza clave en el cambio sociopolítico de la época. Manheim desarrolló la observación que Tocqueville había hecho un siglo antes de que el imaginario democrático era tan poderoso en las sociedades contemporáneas que la participación inclusiva-igualitaria se había convertido en el telos del cambio político institucional. Al mismo tiempo, reconoció que ese cambio podría ocurrir de una forma y con una velocidad tal que la democracia corría el riesgo de anularse a sí misma (para un estudio reciente del tema, véase Karagiannis, 2010, 2013). Unos años más tarde, en 1944, La gran transformación, de Karl Polanyi, aportaba un análisis similar centrándose en la inestabilidad creada por las dinámicas del cambio económico. La idea de la autorregulación del mercado, ideología económica dominante durante la primera mitad del siglo XIX, conllevaba la mercantilización: la tendencia a convertir los bienes en mercancías pese a que estos no fueran ni pudieran ser producidos con el objetivo de ser intercambiados, siendo los más importantes el trabajo, la tierra y el dinero. Para hacer frente a esa mercantilización inadecuada, que era destructiva de la vida social, surgió la "autodefensa de la sociedad", y Polanyi analizó desde esta perspectiva las transformaciones sociales que tuvieron lugar entre mediados del siglo XIX y mitad del XX. Tras haber presenciado el ascenso del fascismo y del socialismo soviético, su mayor preocupación era hasta dónde podía llegar la necesaria autodefensa de la sociedad sin que la libertad fuera puesta en peligro. Pocos años más tarde, tras el final de la Segunda Guerra Mundial, Hanna Arendt, en Los orígenes del totalitarismo (1951), combinaría el análisis de un capitalismo siempre en expansión, que adoptaba la forma del imperialismo, con un análisis del Estado-nación, que exigía de un marco estable para la acción política, para entender las tensiones que se habían producido en las sociedades europeas y que, sin que ello fuera necesario, habían terminado por explotar y propiciar el ascenso del totalitarismo.

Estos autores aportaron potentes diagnósticos de su época utilizando elementos seleccionados de la anterior sociología europea de la modernidad, pero interrogándose al mismo tiempo y cuestionando todas las ideas aceptadas con anterioridad acerca de la regularidad y la previsibilidad de las tendencias de la evolución moderna. Apoyándose en una reconstrucción histórica detallada, detectaron las tensiones inherentes y la fragilidad de los modernos acuerdos sociopolíticos e hicieron hincapié en la contingencia de los resultados históricos: la posibilidad siempre presente de que las cosas hubiesen resultado de otro modo en caso de que los seres humanos hubieran actuado de forma distinta en los momentos claves de la historia.

La reconstrucción que tuvo lugar tras la Segunda Guerra Mundial, lo que se conoció como "los treinta años gloriosos" (Jean Fourastié), provocó en buena medida que los matices y las sutilezas desaparecieran de la sociología de la modernidad. Al llegar 1970, la imagen de Parsons de una modernidad básicamente coherente a la vez que normativamente viable, en la que el cambio social podría suceder de forma suave sin afectar ya a los cimientos institucionales, se había esparcido por Europa, y coexistía con la más reciente imagen 
contrapuesta neomarxista que, si bien es cierto hacía hincapié en las contradicciones, lo hacía de una manera considerablemente determinista.

El debate sociológico sobre la modernidad se reavivó durante las décadas de 1970 y 1980, ocupándose principalmente de dos cuestiones: los pensadores críticos trataban de reconstruir el materialismo histórico -una expresión bastante común en los setenta- a la luz de la relativa estabilidad sociopolítica de las sociedades capitalistas de la época; y reconocieron que un problema común de las teorías funcionalistas y neomarxistas era su objetivismo y su determinismo, que debía ser remediado por el renovado interés en la acción humana en lo que se dio a llamar el "debate acción-estructura". En última instancia, en todo caso, las contribuciones claves a este debate siguieron trazando un retrato demasiado armonioso de la modernidad de finales del siglo XX, vinculando de forma muy apresurada el reconocimiento de las tensiones dentro de la modernidad con los supuestos acerca de la capacidad para equilibrar esas tensiones. Así, Alain Touraine (1992) habló acerca del equilibrio entre la subjetivación y la racionalización; Jürgen Habermas (1981) identificó las tendencias para la colonización del mundo de la vida, pero determinó que la tarea de la teoría crítica era proporcionar formas de contrarrestarlas; y Anthony Giddens (1990) hizo hincapié en las distintas maneras posibles de enfrentarse a las consecuencias de la modernidad, potencialmente desastrosas, pero también potencialmente benignas.

A partir de la década de 1990 y hasta nuestros días, la experiencia respecto de la modernidad se ha vuelto de nuevo más indefinida, y este hecho ha tenido su reflejo en la sociología de la modernidad. De forma significativa, se tenía la percepción de que las sociedades europeas estaban inmersas en un proceso de cambio tan profundo que era necesario hablar de una nueva fase y de una nueva forma de modernidad (Beck, 1986; Wagner, 1994). Conforme se estaba produciendo esta transformación, la interpretación de esta nueva fase emergente de la modernidad se volvió más crítica. La transformación fue interpretada como una experiencia desestructuradora que desmantelaba fenómenos sociales como los de clase, nación o Estado, que habían sido componentes básicos de la modernidad anterior y conceptos claves para analizar dicha modernidad. Tras perder el contacto con los fenómenos, la sociología de la modernidad volvió a hacer hincapié en tendencias de largo recorrido, de las cuales las centrales serán conocidas como la individualización y la globalización, sugiriendo así claramente la idea de que las estructuras sociales dejarían de existir.

La mayoría de los estudiosos de los dos períodos recién descritos mantienen una dependencia demasiado grande de las mismas ideas claves de los orígenes decimonónicos de la sociología europea de la modernidad; ideas que, tras un prolongado proceso de canonización, han sido destiladas hasta quedar exangües. La búsqueda de herramientas conceptuales siempre se lleva a cabo por caminos muy trillados, y estas son simplemente adaptadas a la luz de las observaciones superficiales del tiempo en que son utilizadas, sin preocuparse por la comparación histórica que el uso de esos conceptos lleva implícita, ni por la comprensión de los matices del tiempo en el que uno se encuentra. En cambio, la posible herencia de los estudiosos de principios del siglo XX -para quienes las turbulencias de la época habían hecho descartar la opción de usar conceptos que tuvieran al alcance de la mano- no se tiene apenas en cuenta. 
Tras haber extendido mis observaciones sobre la sociología europea de la modernidad desde su origen en el siglo XIX hasta su evolución y transformación a lo largo del siglo XX, puedo corroborar la afirmación acerca de la improductividad del final del siglo XX y de la actual sociología europea de la modernidad, continuando mi recorrido hasta la siguiente etapa; concretamente, a las reflexiones en torno a las limitaciones espaciales en el alcance analítico de la sociología europea de la modernidad.

El siglo XX sociológico se inaugura con la afirmación de Weber (1930) acerca de los orígenes locales y la significación universal, "tal y como estamos inclinados a pensar", del racionalismo occidental. Y se cierra con el teorema de la globalización. Pero ¿cuánto interés ha mostrado realmente la sociología de la modernidad europea por la modernidad fuera de Europa?

\section{V. ¿CÓMO -O CÓMO NO- AFRONTÓ LA SOCIOLOGÍA EUROPEA LA CUESTIÓN DE LA DINÁMICA ESPACIAL DE LA MODERNIDAD?}

La Revolución Francesa y la Revolución Industrial son a menudo -y en general con aciertopercibidas como las transformaciones sociales o los indicadores a partir de los cuales se establecen los orígenes de la sociología de la modernidad. Sin embargo, ninguna o muy poca atención se les ha prestado a otros acontecimientos determinantemente transformadores que tuvieron lugar en otros lugares, como las distintas declaraciones de independencia americanas en los Estados Unidos, en Haití, y en lo que se ha venido a llamar la América Latina. Manfred Henningsen (1974) ha afirmado elocuentemente que la Revolución Francesa eclipsó a la Revolución Americana dentro de la conciencia europea. Las revoluciones que sucedieron a la Revolución Francesa, por su parte, apenas despertaron interés, al considerarse a priori como simples emuladoras de la misma que no aportaban nada realmente significativo.

Hasta mediados del siglo XIX, los observadores más perspicaces podían todavía relacionar de forma crítica la experiencia europea con otras experiencias que habían tenido lugar en otras partes del mundo, aunque esta relación solía establecerse tan solo con Estados Unidos. Tocqueville y el joven Marx son los ejemplos más elocuentes. A finales del siglo XIX, sin embargo, la dominación que Europa ejercía sobre el resto del mundo era tan pronunciada que resultaba difícil observar otra razón más importante detrás del auge europeo. Esa razón más importante dejó de encontrarse en la forma explícita de una filosofía de la historia, tal y como Hegel había hecho (para una estimulante lectura de Hegel, véase Buck-Morss, 2000), sino en las leyes del cambio sociohistórico que crearon trayectorias de desarrollo, y de las cuales la europea sobresalió por ciertas razones, que varían dependiendo del observador (como la acumulación originaria, la ética protestante, la división social del trabajo y otras). Una relectura contextualizada muestra que los sociólogos europeos de alrededor de 1900 eran bien conscientes del dominio europeo del mundo y que contaban con una visión global de su época. Estaban muy lejos de separar Europa de forma analítica de su contexto global, tal y como tendían a hacer los teóricos posteriores a la Segunda Guerra Mundial. Al mismo tiempo, veían la posición europea en el mundo como el resultado "natural" de la historia mundial hasta aquel momento, y no era una cuestión central en su problemática (para estudiar esa relectura, véase Connell, 2007). 
De forma significativa, a finales del siglo XIX los efectos de la dominación europea tuvieron su expresión fuera de Europa o en sus márgenes geográficos en forma de cambios y de intentos de emulación de los modelos europeos: los conceptos sociológicos europeos se traducen al chino y al japonés; las revoluciones soviética y kemalista son concebidas como pasos progresivos más allá de la experiencia europea (Arnason, 1993; Kaya, 2004); el programa del Congreso Nacional Africano, fundado en Sudáfrica en 1912, se inspira en la idea de la libertad igual. En ese momento, daba la impresión de que algo de "trascendencia universal" había sucedido en Europa e ineludiblemente había de ser experimentado por los seres humanos de las demás partes del mundo.

La primera mitad del siglo XX vino marcada por las guerras globales: los conflictos domésticos y las guerras civiles -que provocaron la aparición de regímenes autoritarios y totalitarios-, y la inestabilidad económica que culminó en la recesión sufrida después de 1929. Ya no era posible reconocer ningún "modelo" dominante. Tras la Segunda Guerra Mundial, no obstante, y ahora bajo la hegemonía de los Estados Unidos, se impuso la imagen de una "sociedad moderna" que, tras la ruptura revolucionaria con la "sociedad tradicional", se embarcaría en una trayectoria bastante suave de "modernización y desarrollo"; una visión que incluso en 1950 habría resultado sorprendente y no habría convencido a casi nadie. Aunque Kemal y Lenin habían insistido, a principios del siglo XX, en la necesidad de un fuerte esfuerzo colectivo y creativo para construir una modernidad propia y adecuada a las convicciones y condiciones de cada uno en medio de un contexto global dominado por Europa, la imagen de una "sociedad moderna" sugería la idea de que bastaba con eliminar los obstáculos que provenían de la "tradición" de manera que cada sociedad pudiera seguir el camino trazado por las sociedades más avanzadas y acabar pareciéndose a ellas. Pese a las críticas que recibió la imagen parsoniana de la modernidad, el debate crítico en torno a esta modernidad, en lo que acabó llamándose el "Norte global", con autores como Habermas, Touraine, Giddens (tal y como se ha comentado antes), perdió de vista la interconexión global o, más exactamente, apenas consideró siquiera la posibilidad de que la historia de las configuraciones sociales desde 1800 pudiera haber creado las condiciones para la modernidad que variaban considerablemente según la localización de una sociedad en la constelación global. Si, en cambio, se toma como punto de partida el presupuesto, bastante obvio, de que la localización en un espacio sociohistórico condiciona de manera determinante la autocomprensión propia y las posibilidades para la acción, ciertos problemas conceptuales emergen para una sociología de la modernidad, algunos de los cuales han sido debatidos en los márgenes de los debates de la corriente dominante. Entre estos aspectos destacan los siguientes:

Primero, la interconexión global sugiere que no existe una dinámica de la modernidad "independiente" o "autodirigida" que pueda hacerse valer en algunas sociedades, pero no en otras, o en unas sociedades antes y en otras más tarde. Lo que hay es más bien una situación de asimetría y dominación en la que el "desarrollo" de las sociedades dominantes tiene, tal y como se ha comentado, influencias adversas en las posibilidades de transformación de las sociedades dominadas. Más que una trayectoria global de "modernización", en la que algunas sociedades están más avanzadas que otras, lo que sucede es que las más avanzadas 
provocan el "desarrollo del subdesarrollo" de las menos desarrolladas. Como consecuencia de esto, la "modernidad" adoptará distintos rasgos en las sociedades dependientes, se distorsionará, no terminará de completarse, o aparecerá de forma comprimida.

En segundo lugar, y pese a que algunos de sus presupuestos más importantes resulten válidos, la anterior teorización depende de una imagen de la modernidad elaborada en el "Norte global" como la única versión posible de la modernidad, o al menos como la referencia fundamental. Otras aproximaciones se centran más en la experiencia de la modernidad en escenarios no europeos. A menudo, de forma implícita al menos, surgen de la idea común de que la modernidad aparece como una ruptura con el pasado. Mientras que la modernidad europea está marcada por una ruptura "endógena" o más bien "elegida por sí misma", el hecho de la dominación de la modernidad europea implica que la ruptura es impuesta sobre las sociedades no europeas. El caso más claro de esto es la rotunda dominación colonial, tal y como se ha examinado en los estudios poscoloniales, pero para los análisis basados en las experiencias será preciso establecer distinciones entre las distintas variedades de experiencias y situaciones coloniales, que van desde la interacción asimétrica entre las sociedades europeas y las no europeas que han mantenido su forma de gobierno -como China y Japón-, las siempre difícilmente catalogables "sociedades de asentamiento" -en las que los grupos de población de descendientes europeos interactúan con grupos de población nativa y, en algunos casos, con grupos que sufrieron migración forzada como los esclavos, como en las Américas, Sudáfrica y Australia-, y las sociedades colonizadas en el sentido estricto del término, como en la mayor parte de África e India (para estudios anteriores, véase Hartz, 1964; Ribeiro, 1971).

En tercer lugar, la asimetría de las transformaciones "modernas" que existen también en el Norte es bien conocida, pero pocas veces ha sido analizada en estos términos. Tras la Revolución Francesa y las conquistas napoleónicas, la mayor parte de Europa se vio enfrentada a nuevos acontecimientos sociopolíticos a los que era preciso dar respuesta (véase el primer trabajo de Koselleck, 1974, sobre Prusia, como un ejemplo de su trabajo en historia conceptual). Los observadores europeos percibieron el auge de Estados Unidos a partir del final del siglo XIX, y más especialmente a partir de la Primera Guerra Mundial, como la aparición de una segunda modernidad de cariz superior (Wagner, 1999; véase también Offe, 2004), y pusieron así sobre la mesa el tema de las distintas variedades de la modernidad, si bien fue algo que apenas tuvo eco en la sociología. La Dialéctica de la Ilustración, de Theodor Adorno y Max Horkheimer, punto de referencia del análisis crítico de la modernidad, fue escrita en Los Ángeles en 1944, pero no contiene reflexión alguna acerca de las diferencias entre la Alemania nazi, la Unión Soviética estalinista y los Estados Unidos de la época.

Las tres cuestiones que acabamos de mencionar asumen la interconexión global, pero mantienen también un sentido de la singularidad de las distintas sociedades y de las trayectorias que estas siguen. Un nuevo desafío, en cuarto lugar, y tal y como se ha mencionado al comienzo, surge del hecho de que la interconexión global implica el movimiento a través de las fronteras no solo de las mercancías, sino también de las personas y las ideas. Las sociedades americanas, por ejemplo, están constituidas por poblaciones indígenas, poblaciones esclavas 
de origen africano, y pobladores europeos, tal y como investiga el debate en torno a las variedades de la experiencia colonial. Pero la emigración, sea esta forzada o voluntaria, de un considerable número de personas implica también transformaciones de las sociedades africanas y europeas que apenas han sido consideradas como constitutivas de condiciones particulares para la expresión de la modernidad. Los orígenes del totalitarismo, de Hannah Arendt -a la que hemos hecho referencia anteriormente por otras razones-, sigue siendo una de las pocas obras que mantiene un propósito conceptual que está basado en el reflejo de los cambios en la composición sociocultural de las sociedades y en su impacto en la autocomprensión de las mismas.

\section{CONCLUSIONES PARA UNA SOCIOLOGÍA MUNDIAL DE LA MODERNIDAD}

La sociología europea de la modernidad ha de ser superada por una sociología mundial de la modernidad, y no solamente en el sentido de "globalizar" un debate que ha sido "provincial" durante demasiado tiempo. "Europa" y el "mundo" (o más bien, "la Tierra", "el globo") pueden ser tomados como una referencia espacial, geográfica. Pero el asunto en cuestión es distinto y más extenso. Las sociología europea de la modernidad, tal y como se ha apuntado anteriormente, ha constituido "Europa" (y después "occidente" o "el Norte global") como su "mundo", en el sentido arendtiano de crear y tener algo en común con aquellos que habitan un espacio común (véase Karagiannis y Wagner, 2007). Pero no ha constituido un "mundo" inclusivo, habitado por todos los seres humanos de la Tierra, mucho menos si se tiene en cuenta el hecho de que un número demasiado elevado de estos habitantes, sobre todo los procedentes del "Sur global", no estuvieron implicados en la creación de este mundo, y que cuando se establecía algún tipo de comunicación entre ellos y los sociólogos europeos de la modernidad, estas eran siempre enormemente asimétricas.

No quiere esto decir que la sociología europea de la modernidad no generase percepciones válidas. Pero estas no se encuentran a simple vista, al alcance de cualquiera que sea capaz de leer, sino que para conseguir salir al primer plano han de llegar a través de una ampliación de la comunicación en el hacer mundo, para la que son precisas algunas condiciones que confiemos en que hayan podido ser dilucidadas en el transcurso de estas reflexiones. El objetivo de estas escuetas conclusiones es dar una idea general, bastante esquemática, de algunos de los posibles temas para una comunicación tan ampliada.

Tal y como se ha dejado apuntado al inicio, la sociología europea de la modernidad planteó como hipótesis una drástica ruptura con el pasado, que supuso la aparición de unos seres humanos nuevos y de unas relaciones sociales menos sustantivas; es decir, de individuos que se relacionan los unos con los otros a través de la racionalidad instrumental, y de nuevas formas sociales, que son los contextos en los que estos seres humanos son a la vez creados y mantenidos. Tal y como hemos visto, tanto las visiones normativas como las aproximaciones analíticas variaron de forma considerable, y pocos consideraron la nueva configuración como algo estable y sostenible. Pero podemos indicar tres claves conceptuales que eran comunes a la mayoría de los estudiosos y que pueden servirnos de guía en nuestro intento de recuperación y ampliación: el concepto de ruptura, la visión del 
ser humano como individuo autónomo, y la visión de la racionalidad instrumental como la actitud predominante de este individuo.

Pese a que los estudiosos del siglo XIX fueron perspicaces observadores del drástico cambio social, su noción de la ruptura cayó en la exageración. Europa ni abandonó su historia, ni se liberó de los entrelazados vínculos que la unían a otras regiones del mundo para embarcarse en una senda de crecimiento endógeno. El concepto de ruptura apunta más a un resurgir intelectual que a una situación nueva desde el punto de vista sociopolítico. La separación entre el horizonte de expectativas del espacio de la experiencia permitió interpretar la Revolución Francesa como un nuevo comienzo político, a partir del cual la legitimidad del poder político y la justificación de la acción política ya no precisarían de fuentes externas. También permitió la conexión entre el cada vez mayor uso del poder productivo inanimado, lo que se Ilamaría la Revolución Industrial, con la idea de que la liberación de las fuerzas del mercado sirve para poder disfrutar plenamente de los frutos de las nuevas tecnologías. Ni este nuevo comienzo político sucedió ni la conexión económico-intelectual resultó lo suficientemente convincente. De lo que no cabe duda es de que se creó un imaginario político y económico que configuró muchas de las acciones que tendrían lugar a lo largo del siglo XIX. Aparte de una ruptura profunda con el pasado, dicha reparación sugería que las sociedades "modernas" tenían la capacidad de instituirse a sí mismas; y de reinstituirse en caso de que una institucionalización previa hubiese resultado deficiente. Dicho de otro modo, se abrió a escrutinio la cuestión de la fundación de una entidad política, y se legitimó, para el uso de los teóricos de la modernidad, el procedimiento por el cual se podía cuestionar-criticar- estas fundaciones.

Entre las fundaciones propuestas de la modernidad, el dominio a través de la racionalidad instrumental ocupó un lugar predominante, pero no lo hizo exento de críticas. Para explorar en profundidad tanto el compromiso con el dominio instrumental como a sus críticos, resulta útil distinguir entre los distintos "objetos" de ese dominio: la naturaleza, uno mismo, y los otros seres humanos. Esta distinción permitirá también establecer un debate más profundo acerca del compromiso con la autonomía.

El sometimiento de la naturaleza al dominio humano, pese a ser una preocupación conocida desde la antigüedad, se convierte en un horizonte de posibilidades a partir de principios del siglo XIX. A lo largo de los dos últimos siglos, el uso de la tecnología a través de lo que ahora se conoce como tres revoluciones industriales -basadas en la máquina de vapor; la electricidad, la química y el motor de combustión; y los aparatos nucleares y electrónicos- transformó radicalmente el mundo. A partir del romanticismo y el Fausto de Goethe, sin embargo, las otras formas de relación con la naturaleza no han sido nunca abandonadas del todo, ni en Europa, ni mucho menos en otras partes del planeta. Pero durante mucho tiempo se suponía que la Tierra no tenía límites significativos, de manera que las consecuencias negativas del dominio instrumental -la contaminación en el sentido más amplio del término- podrían desplazarse a cualquier otra parte, lejos de aquellos que la producían. Hoy en día, la continuación del dominio instrumental sobre la naturaleza pone en peligro la misma sostenibilidad de la vida humana sobre la Tierra. Es precisa una forma 
distinta de compromiso con la Tierra, y esta solo podrá surgir de la creación de un mundo diferente que sea sostenido en común.

La creación de un mundo de estas características requiere la percepción de que, con respecto a la habitabilidad de la Tierra, el sujeto del dominio ha de ser la propia humanidad, mientras que al mismo tiempo ese hacer mundo necesita tener en cuenta el grado diferencial en que los seres humanos han contribuido a transformar el mundo, se han beneficiado de él, y han sufrido o sufrirán por su causa. Uno de los problemas conceptuales claves que surgieron durante la modernidad europea, sin embargo, es que el ser humano individual era visto, cada vez más, como la única fuente de acción, tanto en términos de justificaciones como en la práctica real, y de que por lo tanto dicho mundo surgiría solo como el agregado de acciones individuales. Junto con el presupuesto de que estos individuos considerarían como actitud predominante la racionalidad instrumental antes que el compromiso hermenéutico, el espacio social que habitamos no es un mundo creado a través de la comunicación, sino un espacio sin sentido marcado por las consecuencias no intencionadas resultado de numerosas y separadas acciones individuales. Esto es lo que Hannah Arendt (1958) Ilamó "pérdida de mundo", la mayor amenaza a la que está expuesta la condición humana actual.

Más que una propiedad del individuo, es más apropiado decir que la autonomía surge de la interacción en contextos de reconocimiento mutuo, y del reconocimiento de las bases naturales de la vida humana, tal y como se ha expuesto antes. Esta sugerencia incorpora el requisito adicional de un equilibrio adecuado entre la autonomía individual y la autodeterminación colectiva, un tema con una larga tradición en la modernidad europea. En la forma de pensar europea ha habido y todavía hay un sesgo conceptual y sociocultural que hace hincapié en la autonomía del individuo frente a la colectividad (véase Wagner, 2008; Karagiannis y Wagner, 2013), pero no trataremos más este tema en términos generales. Desde una perspectiva sociológica mundial, la relación entre las colectividades tiene una importancia capital, y las condiciones internas de la libertad dentro de una colectividad están en sí mismas condicionadas por la relación entre colectividades (Rosich, 2013).

La libertad presupone la igualdad, ya hace tiempo que esto se ha dicho (véase Raaflaub, 1996). Pero en el siglo XIX, el compromiso con la libertad estaba sujeto a su limitación a un restringido grupo de seres humanos que cumplían ciertos requisitos, los cuales iban variando según las circunstancias históricas. Al mismo tiempo, el compromiso moderno con la libertad facilitaba el recurso normativo para reivindicar una libertad igual, y la inclusión de las mujeres y los trabajadores en igualdad de condiciones en las sociedades europeas constituyó la línea más importante de contestación y de cambio social durante el siglo XIX y buena parte del XX. La inclusión igual fue así aclamada como el mayor logro de la modernidad europea a mediados del siglo XX. Sin embargo, el ejercicio de la dominación colonial a manos de sociedades igualitarias en el ámbito doméstico fue un hecho convenientemente olvidado. No es en absoluto exagerado sugerir que la inclusión igualitaria en el ámbito doméstico venía a menudo antecedida del refuerzo de las fronteras y del incremento de la dominación sobre los otros fuera de la entidad política propia. 
Las anteriores reflexiones no son más que un punto de partida, y podrán ser continuadas de manera provechosa solo a través de un compromiso más intenso con la situación mundial en la que la humanidad está inmersa en nuestros días (véase Strong, 2013, entre otros). Deberían haber bastado, en todo caso, para mostrar que, al investigar su propio siglo XIX, los sociólogos europeos de la modernidad identificaron las cuestiones conceptuales claves con una intención de "teorizar la modernidad". Al mismo tiempo, identificaron incorrectamente las formas en que esos conceptos se podrían aplicar a su situación. Más que observar una ruptura en la vida social en torno al 1800, presenciaron el principio de la dominación europea del mundo. Más que observar cómo se rompían todos los vínculos sociales que conducen al imparable ascenso de la racionalidad instrumental individual, presenciaron los principios de una transformación material del mundo que, al crear en el ámbito doméstico la dominación de clase y la exclusión, fomentó la construcción de nuevos vínculos sociales y la exclusión de los otros fuera de la sociedad propia; y todo eso se llevó a cabo embarcándose en un camino de crear beneficios cerca de casa y desplazar las cargas a cualquier otra parte, con lo que, más de un siglo después, se pondría en peligro la habitabilidad del planeta.

La sociología europea de la modernidad ha creado algunas herramientas para comprender nuestra condición humana actual. Sin embargo, para poder utilizarlas de manera provechosa, es preciso primero reconocer las maneras en las que dicha sociología afrontó los problemas dentro del espacio experiencial e interpretativo del siglo XIX europeo, y embarcarse después en un trabajo -conceptual e histórico- de recuperación, ampliación y reconsideración. Los debates del siglo XIX tienen una trascendencia global que va más allá de su propio contexto, porque ese contexto era el de la dominación europea del mundo. Pero en el momento en que este contexto es analizado y los interlocutores son debidamente contextualizados, adquieren de nuevo toda su importancia. El objetivo de estas reflexiones es contribuir a ese trabajo de recuperación, ampliación y reconsideración.

\section{BIBLIOGRAFÍA}

Arendt, Hannah (1951): The origins of totalitarianism, Harcourt, Brace and World, Chicago. (1958): The human condition, The University of Chicago Press, Chicago.

Arnason, Johann P. (1993): The future that failed: origins and destinies of the Soviet model, Routledge, London.

Baily, C. A. (2004): The birth of the modern world, 1780-1914, Blackwell, Oxford.

Beck, Ulrich (1986): Risikogesellschaft, Suhrkamp, Frankfurt/M.

Borch, Christian (2001): The politics of crowds. An alternative history of sociology, Cambridge University Press, Cambridge.

Boudon, Raymond (1984): La Place du désordre, Presses Universitaires de France, Paris.

Buck-Morss, Susan (2000): "Hegel and Haiti", Critical Inquiry, 26 (4), pp. 821-865.

Castoriadis, Cornelius (1975): The imaginary institution of society, MIT Press, Cambridge, Mass.

Chakrabarty, Dipesh (2009): “The climate of history: four theses", Critical Inquiry, 35 (2), pp. 197-222. 
Connell, Raewyn (2007): Southern theory, Polity Press, Cambridge.

Dahrendorf, Ralph (1959): Class and class conflict in industrial society, Routledge and Kegan Paul, London.

Giddens, Anthony (1990): The consequences of modernity, Polity Press, Cambridge.

Habermas, Jürgen (1981): Theorie des kommunikativen handelns, Suhrkamp, Frankfurt/M.

Halperin, Sandra (2004): War and social change in modern Europe, Cambridge University Press, Cambridge.

Hartz, Louis (1964): The founding of new societies, Harcourt Brace Jovanovich, San Diego.

Heilbron, Johan (1985): “Les métamorphoses du durkheimisme, 1920-1940", Revue Française de Sociologie, 26 (2), pp. 203-237.

Henningsen, Manfred (1974): Der fall Amerika, List, Munich.

Karagiannis, Nathalie (2010): "Democracy as a tragic regime: democracy and its self-cancellation", Critical Horizons, 11 (1), pp. 35-49.

(2013): "Democratic surplus and democracy-in-failing", en Gerard Rosich y Peter Wagner (eds.): Political modernity in the $21^{\text {st }}$ century: freedom, democracy, solidarity (en preparación).

Karagiannis, Nathalie y Peter Wagner (eds.) (2007): Varieties of world-making: beyond globalization, Liverpool University Press, Liverpool.

(2013): "The freedom of the ancients compared to the one of the moderns", en Johann P. Arnason, Kurt Raaflaub y Peter Wagner (eds.): The Greek polis and the invention of democracy: a politico-cultural transformation and its interpretations, Blackwell, Oxford.

Kaya, Ibrahim (2004): Social theory and later modernities: the Turkish experience, Liverpool University Press, Liverpool.

Koselleck, Reinhart (1975): Preussen zwischen Reform und revolution, Klett, Stuttgart. (1979): Vergangene zukunft. Zur semantik geschichtlicher zeiten, Suhrkamp, Frankfurt/M.

Lefort, Claude (1986): Essais sur le politique, xix-xxe siècles, Seuil, Paris. (1994): Ecrire à l'épreuve du politique, Calmann-Lévy, Paris.

Lyotard, Jean-François (1979): La condition postmoderne, Minuit, Paris.

Mannheim, Karl (1980 [1937]): Man and society in an age of reconstruction, Routledge and Kegan Paul, London.

Mayer, Arno (1981): The persistence of the Old Regime, Pantheon, New York.

Offe, Claus (2004): Selbstbetrachtung aus der Ferne. Tocqueville, Weber und Adorno in den Vereinigten Staaten, Suhrkamp, Frankfurt/M.

Osterhammel, Jürgen (2008): Die verwandlung der welt. Eine geschichte des 19. Jahrhunderts, Beck, Munich.

Parsons, Talcott (1937): The structure of social action, McGraw-Hill, New York.

Polanyi, Karl (1985 [1944]): The great transformation, Beacon, Boston.

Pomeranz, Kenneth (2000): The great divergence: China, Europe and the making of the world economy, Princeton University Press, Princeton.

Raaflaub, Kurt (1996): Die entdeckung der freiheit, Beck, Munich. 
Ribero, Darcy (1971): The Americas and civilization, Dutton, New York.

Rosich, Gerard (2013): "Autonomy in and between polities", en Gerard Rosich y Peter Wagner (eds.): Political modernity in the twentieth century: freedom, democracy, solidarity (en preparación).

Stråth, Bo: Three utopias of peace and the search for a political economy (en preparación).

Strong, Tracy (2013): "The world as we find it", en Gerard Rosich y Peter Wagner (eds.): Political modernity in the twentieth century: freedom, democracy, solidarity (en preparación).

Touraine, Alain (1965): Sociologie de I'action, Seuil, Paris.

(1992): Critique de la modernité, Fayard, Paris.

Wagner, Peter (1990): Sozialwissenschaften und Staat in Kontinentaleuropa: Frankreich, Italien, Deutschland, 1890-1980, Campus, Frankfurt/M.

(1991): "Science of society lost: on the failure to establish Sociology in Europe during the 'classical' period discourses on society", en Peter Wagner, Björn Wittrock y Richard Whitley (eds.): The shaping of the social science disciplines, Kluwer, Dordrecht, pp. 219-245.

(1994): A sociology of modernity: liberty and discipline, Routledge, London.

(1999): "The resistance that modernity constantly provokes. Europe, America and social theory", Thesis Eleven, 58, pp. 35-58.

(2001): Theorizing modernity, Sage, London.

(2008): Modernity as experience and interpretation, Polity Press, Cambridge.

(2013): "Transformations of democracy: towards a history of political thought in long-term perspective", en Johann P. Arnason, Kurt Raaflaub y Peter Wagner (eds.): The Greek polis and the invention of democracy: a politico-cultural transformation and its interpretations, Blackwell, Oxford.

Weber, Max (1930 [1904-5/1920]): The protestant ethic and the spirit of capitalism, Allen \& Unwin, London.

Wittrock, Björn (1985): "Dinosaurs or dolphins? The rise and resurgence of the research-oriented university", en Björn Wittrock y Aant Elzinga (eds.): The university research system. Public policies for the home of scientists, Alqvist and Wiksell, Stockholm. 